\title{
Honey Yield Forecast Using Radial Basis Functions
}

\author{
Humberto Rocha ${ }^{1,2}$ and Joana Dias ${ }^{1,2}$ \\ 1 CeBER and Faculdade de Economia, Universidade de Coimbra, \\ 3004-512 Coimbra, Portugal \\ 2 INESC-Coimbra, \\ 3030-290 Coimbra, Portugal \\ hrocha@mat.uc.pt, joana@fe.uc.pt
}

\begin{abstract}
Honey yields are difficult to predict and have been usually associated with weather conditions. Although some specific meteorological variables have been associated with honey yields, the reported relationships concern a specific geographical region of the globe for a given time frame and cannot be used for different regions, where climate may behave differently. In this study, Radial Basis Function (RBF) interpolation models were used to explore the relationships between weather variables and honey yields. RBF interpolation models can produce excellent interpolants, even for poorly distributed data points, capable of mimicking well unknown responses providing reliable surrogates that can be used either for prediction or to extract relationships between variables. The selection of the predictors is of the utmost importance and an automated forward-backward variable screening procedure was tailored for selecting variables with good predicting ability. Honey forecasts for Andalusia, the first Spanish autonomous community in honey production, were obtained using RBF models considering subsets of variables calculated by the variable screening procedure.
\end{abstract}

Keywords: Honey Yield, Weather, Radial Basis Functions, Variable Screening

\section{Introduction}

Honey has been used by humans for at least 8000 years [2]. Its production and economic interest have grown to the present day. However, annual production has large fluctuations mainly associated with weather conditions $[5,18]$. While some studies claim that temperatures in May, June and July are particularly important predictors of honey yields $[6,7,9]$, other claim that variation in honey yields could be more related to March temperatures and rainfall, sunshine and temperature from April to July [4,5]. In fact, the precise relationships between weather conditions and honey yields are not well established yet. Furthermore, the relationships between weather conditions and honey yields already reported concern a specific geographical region of the globe for a given time window and cannot be used for different regions, where climate may behave differently. 
In this study, the relationships between honey yield and a large number of weather variables were explored aiming to forecast honey production in Andalusia, a Spanish autonomous community. Radial basis functions (RBF) were used to interpolate the data and provide the predictive models. RBF regression has been successfully applied in different contexts, including aeronautics $[13,14]$ or radiotherapy $[16,17]$. RBF models proved to mimic well unknown responses providing reliable surrogates that can be used either for prediction or to extract relationships between variables [15]. The selection of the predictors is of the utmost importance and a variable screening approach is presented. The remainder of the paper is organized as follows. Honey production and weather data in Andalusia are presented in the next Section. In Section three we briefly describe RBF interpolation. Section four presents the variable screening strategy proposed. Results are presented in Section five followed by the conclusion's Section.

\section{Honey production and weather data in Andalusia}

Spain is the largest EU honey producer which is the second world producer after China [3]. Andalusia is the first Spanish autonomous community regarding honey production (6887 tonnes) and honey bee hives (562503 units), according to the latest statistical data released by the Spanish Ministry of Agriculture, Food and Environment [1]. There are two different types of honey bee hives in Andalusia: fixed comb hives - traditional hive types that require permanent damage of the comb for harvesting - and movable comb hives - modern hive types that include top-bar hives, horizontal frame hives or vertical stackable frame hives. In Andalusia, about $97 \%$ of the hives are modern hive types and we will only consider these type of hives for our forecast.

Andalusia is in the south of Spain, east of Portugal and the Atlantic Ocean and north of the Mediterranean Sea and Africa. It is the second largest in area of the Spanish autonomous communities with $87268 \mathrm{~km}^{2}$. Andalusia is divided into eight provinces - Almeria, Cádiz, Córdoba, Granada, Huelva, Jaén, Málaga and Seville - with distinct weather conditions. It is covered by a set of automated agroclimatic stations that can perform various meteorological measurements [8]. Since the honey yields of the different provinces are also available, instead of averaging different weather conditions causing a larger weather bias, forecast was made for each region considering the corresponding weather data. Only the five largest honey producer provinces (Córdoba, Granada, Huelva, Málaga and Seville) were considered. Historical data of honey yields and number of hives for the time frame in study (2001-2015) for each province is presented in Table 1. Historical data of the weather variables considered - rainfall $(\mathrm{mm})$, evapotranspiration $(\mathrm{mm})$, minimum temperature $\left({ }^{\circ} \mathrm{C}\right)$, maximum temperature $\left({ }^{\circ} \mathrm{C}\right)$, mean temperature $\left({ }^{\circ} \mathrm{C}\right)$ and relative humidity $(\%)$ - are available in Appendix. 
Table 1. Tonnes of honey yields and number of hives for the five largest honey producer provinces of Andalusia.

\begin{tabular}{|c|c|c|c|c|c|c|c|c|c|c|}
\hline \multirow[b]{2}{*}{ Year } & \multicolumn{2}{|c|}{ Córdoba } & \multicolumn{2}{|c|}{ Granada } & \multicolumn{2}{|c|}{ Huelva } & \multicolumn{2}{|c|}{ Málaga } & \multicolumn{2}{|c|}{ Seville } \\
\hline & $\begin{array}{c}\text { Honey } \\
\text { Yield }\end{array}$ & $\begin{array}{c}\# \\
\text { hives }\end{array}$ & $\begin{array}{c}\text { Honey } \\
\text { Yield }\end{array}$ & $\begin{array}{c}\# \\
\text { hives }\end{array}$ & $\begin{array}{c}\text { Honey } \\
\text { Yield }\end{array}$ & $\begin{array}{c}\# \\
\text { hives }\end{array}$ & $\begin{array}{c}\text { Honey } \\
\text { Yield }\end{array}$ & $\begin{array}{c}\# \\
\text { hives }\end{array}$ & $\begin{array}{c}\text { Honey } \\
\text { Yield }\end{array}$ & $\begin{array}{c}\# \\
\text { hives }\end{array}$ \\
\hline 2001 & 268 & 44739 & 504 & 33600 & 990 & 66000 & 761 & 63398 & 1131 & 76644 \\
\hline 2002 & 297 & 49529 & 586 & 39083 & 1323 & 66150 & 872 & 62263 & 1369 & 80989 \\
\hline 2003 & 193 & 53700 & 595 & 39690 & 944 & 72580 & 966 & 64404 & 1499 & 90847 \\
\hline 2004 & 149 & 41461 & 656 & 43723 & 514 & 51360 & 765 & 63757 & 894 & 71238 \\
\hline 2005 & 126 & 41901 & 671 & 44757 & 433 & 61832 & 438 & 67417 & 827 & 82692 \\
\hline 2006 & 473 & 42987 & 680 & 45357 & 779 & 64954 & 697 & 69669 & 879 & 82694 \\
\hline 2007 & 756 & 45800 & 565 & 43466 & 992 & 66156 & 1138 & 71145 & 808 & 79515 \\
\hline 2008 & 435 & 43531 & 522 & 40155 & 941 & 67200 & 987 & 70488 & 950 & 93880 \\
\hline 2009 & 616 & 43990 & 546 & 42020 & 987 & 65784 & 900 & 66651 & 1083 & 97500 \\
\hline 2010 & 600 & 44804 & 568 & 43665 & 891 & 66015 & 915 & 67783 & 1066 & 97463 \\
\hline 2011 & 749 & 46825 & 594 & 45671 & 882 & 67813 & 1000 & 67450 & 964 & 94315 \\
\hline 2012 & 242 & 48385 & 613 & 47127 & 674 & 67425 & 761 & 76069 & 954 & 94173 \\
\hline 2013 & 675 & 45000 & 633 & 48705 & 972 & 67041 & 937 & 78093 & 1270 & 97314 \\
\hline 2014 & 458 & 45825 & 660 & 50791 & 1105 & 69060 & 939 & 78254 & 1471 & 101463 \\
\hline 2015 & 442 & 58935 & 700 & 53856 & 1066 & 71056 & 876 & 97316 & 1479 & 106494 \\
\hline
\end{tabular}

\section{Radial Basis Functions Models}

RBF interpolation models can produce response surfaces capable of to exploring the nonlinear relationships between different input or explanatory variables and output or response variable(s). Moreover, RBFs can be used to predict unknown responses given the values of the explanatory variables. It was shown that stochastic models coincide with the corresponding RBF models [21]. For a set of data points in a high dimensional space, even if scarce or poorly distributed, a RBF interpolation model (surface) can always be calculated. However, the RBF model behavior between data points, is highly dependent on the basis function considered. For a given data set, some RBFs can provide desirable trends while other may exhibit undesirable trends. Thus, instead of a typical a priori choice based either on the literature or on authors' preferences, it is advisable to select the most adequate RBF for the data set at hand considering numerical metrics [15]. A brief description of RBF interpolation is provided next.

\subsection{RBF interpolation}

Let $y(\mathbf{x})$ denote the response for a given data point $\mathbf{x}$ of $n$ components (variables) such that the value of $y$ is only known at a finite set of $N$ input data points $\mathbf{x}^{1}, \ldots, \mathbf{x}^{N}$, i.e., only $y\left(\mathbf{x}^{k}\right)(k=1, \ldots, N)$ are known. A RBF interpola- 


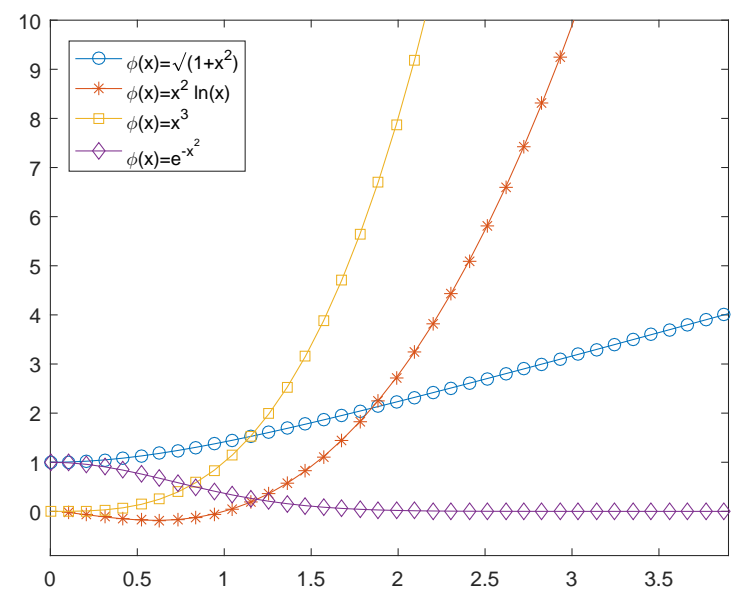

Fig. 1. Graphs of multiquadric, $\phi(x)=\sqrt{1+x^{2}}$, thin plate spline, $\phi(x)=x^{2} \ln (x)$, cubic spline, $\phi(x)=x^{3}$, and Gaussian, $\phi(x)=\exp \left(-\mathrm{x}^{2}\right)$ RBFs.

tion model $h(\mathbf{x})$ can be generically represented as

$$
h(\mathbf{x})=\sum_{j=1}^{N} \alpha_{j} \phi\left(\left\|\mathbf{x}-\mathbf{x}^{j}\right\|\right),
$$

where $\phi(x)$ is the selected RBF, $\alpha_{j}$ are the coefficients determined by the interpolation equations $h\left(\mathbf{x}^{k}\right)=y\left(\mathbf{x}^{k}\right)(k=1, \ldots, N),\left\|\mathbf{x}-\mathbf{x}^{j}\right\|$ corresponds to the parameterized distance between $\mathbf{x}$ and $\mathbf{x}^{j}$,

$$
\left\|\mathbf{x}-\mathbf{x}^{j}\right\|=\sqrt{\sum_{i=1}^{n}\left|\theta_{i}\right|\left(x_{i}-x_{i}^{j}\right)^{2}},
$$

and $\theta_{1}, \ldots, \theta_{n}$ are scalars [15]. Coefficients $\alpha_{1}, \ldots, \alpha_{N}$ in Eq. (1) are computed for fixed parameters $\theta_{i}$ using the interpolation equations of the following linear system:

$$
\sum_{j=1}^{N} \alpha_{j} \phi\left(\left\|\mathbf{x}^{k}-\mathbf{x}^{j}\right\|\right)=y\left(\mathbf{x}^{k}\right), \quad \text { for } k=1, \ldots, N .
$$

Multiquadric, $\phi(x)=\sqrt{1+x^{2}}$, thin plate spline, $\phi(x)=x^{2} \ln x$, cubic spline, $\phi(x)=x^{3}$, and Gaussian, $\phi(x)=\exp \left(-\mathrm{x}^{2}\right)$, are examples of RBFs that are commonly used to model linear, almost quadratic and cubic growth rates, as well as exponential decay of the response, respectively [12] - see Fig. 1. 


\subsection{Cross-validation}

Calculation of the RBF model $h(\mathbf{x})$ in Eq. (1) requires the selection of a RBF $\phi(x)$ and the choice of model parameters $\theta_{1}, \ldots, \theta_{n}$. While selection of the most appropriate RBF for the given data set can be done iteratively by testing the different possible choices of $\phi(x)$, there is an infinite number of possible choices for $\theta_{1}, \ldots, \theta_{n}$. For different fixed sets of model parameters $\theta_{1}, \ldots, \theta_{n}$, distinct models with different behaviors between data points are calculated for a given selection of $\phi(x)$. Cross-validation (CV) can be used for model parameter tuning leading to models with enhanced prediction capability [19]. Furthermore, the most appropriate basis function $\phi(x)$ can be numerically computed using prediction accuracy (CV error) as main criterion. The leave-one-out $\mathrm{CV}$ procedure can be used in model parameter tuning for RBF interpolation [15]:

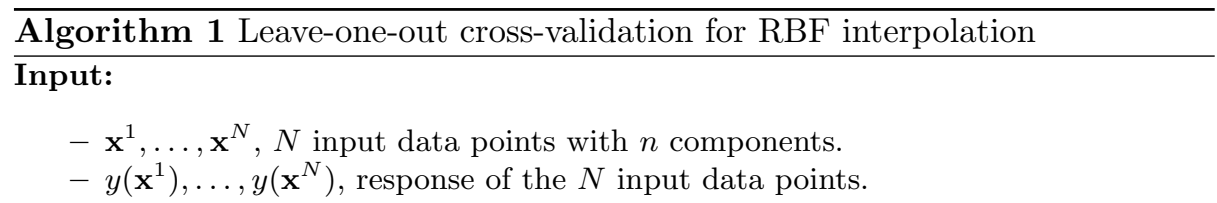

\section{Iteration:}

1. Fix a set of model parameters $\theta_{1}, \ldots, \theta_{n}$.

2. For $j=1, \ldots, N$, construct the RBF model $h_{-j}(\mathbf{x})$ of the data points $\left(\mathbf{x}^{k}, y\left(\mathbf{x}^{k}\right)\right)$ for $1 \leq k \leq N, k \neq j$.

3. Set prediction error as the following $\mathrm{CV}$ root mean square error:

$$
E^{C V}\left(\theta_{1}, \ldots, \theta_{n}\right)=\sqrt{\frac{1}{N} \sum_{j=1}^{N}\left(h_{-j}\left(\mathbf{x}^{j}\right)-y\left(\mathbf{x}^{j}\right)\right)^{2}} .
$$

The goal of model parameter tuning by $\mathrm{CV}$ is to find $\theta_{1}, \ldots, \theta_{n}$ that minimize the $\mathrm{CV}$ error, $E^{C V}\left(\theta_{1}, \ldots, \theta_{n}\right)$, so that the interpolation model has the highest prediction accuracy when $\mathrm{CV}$ error is the measure. Using different $\theta_{i}$ allows the model parameter tuning to scale each variable $x_{i}$ based on its significance in modeling the variance in the response, thus, has the benefit of implicit variable screening built in the model parameter tuning.

\section{Variable Screening}

A regression model with too many input variables may have several disadvantages including an increasing difficulty on model parameter optimization or data overfitting. A standard variable screening procedure aims to identify a subset of the input variables that have significant impact on the response $y(\mathbf{x})$. In 
other words, if the change of $y(\mathbf{x})$ with respect to a given variable is negligible, then the subset of the input variables should not include such variable.

Variable screening methods that require the response values for specific input vectors, such as ANOVA, cannot be used in this study. Other existing variable screening techniques require specific conditions. E.g., the main effects estimate (MEE) method, proposed by Tu and Jones [20], generally requires a uniform distribution of the existing input vectors in a rectangular domain of the input space which is not the case.

Forward or backward variable screening methods are typically used to determine the explanatory power of input variables of polynomial models (linear regression) that are independent of the data distribution. Here, we assume that forward and backward variable screening methods are valid for variable selection in nonlinear models. In general, under this assumption, the forward and backward variable screening methods can be formally applied for variable selection if the data is fitted by a regression model that is independent of data distribution. We propose a generalization of a combined forward-backward variable screening procedure, described in Algorithm 2, that is based in the predicting ability instead of the typically used coefficient of determination $\left(R^{2}\right)$. In the first iteration of this procedure, input vectors with a single variable at a time are fitted using RBF models (1) and the CV error (3). The best model and corresponding variable correspond to the smallest CV error which is a proxy for the prediction error. In the second iteration, input vectors with two variables, fixing the one found in the first iteration, are fitted using RBF models (1) and the CV error (3). The second variable that, along with the fixed first variable, forms the best prediction pair of variables is fixed for the third iteration. This procedure continues until the prediction error (CV error) fails to improve. Note that, at successful iteration $k$, we may not find the best subset of $k$ predicting variables, i.e. the set of $k$ variables that corresponds to the smallest $\mathrm{CV}$ error. E.g., at iteration two we only tested $n-1$ possibilities - the pairs constituted by the first fixed variable and each of the remaining $n-1$ variables - instead of

all possibilities $-\left(\begin{array}{l}n \\ 2\end{array}\right)=\frac{n !}{2 !(n-2) !}$. Thus, at the end of the forward procedure we proceed with a backward procedure aiming to further improve the CV error. The rational behind this procedure is identical except that instead of being added, a variable is removed at each iteration.

\section{Computational results}

Our tests were performed on a $2.60 \mathrm{Ghz}$ Intel Core i7-6700HQ PC with 16 GB RAM and we used MATLAB (R2016a) [10]. Optimal RBF model parameters $\theta_{1}, \ldots, \theta_{n}$ of (3) were computed by minimizing the CV error using a MATLAB implementation (fminsearch) of a derivative-free optimization algorithm called Nelder-Mead [11]. The optimal CV error obtained for the different basis functions tested was used as proxy of their prediction ability [15]. Thin plate spline RBF was selected as basis function since the corresponding RBF models presented the lowest CV errors. 


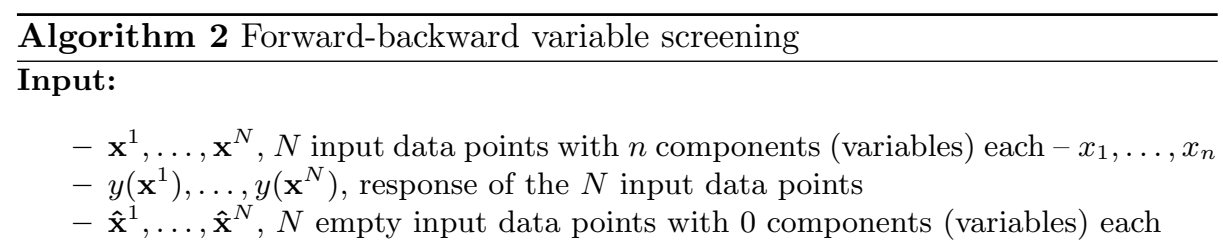

\section{Forward screening:}

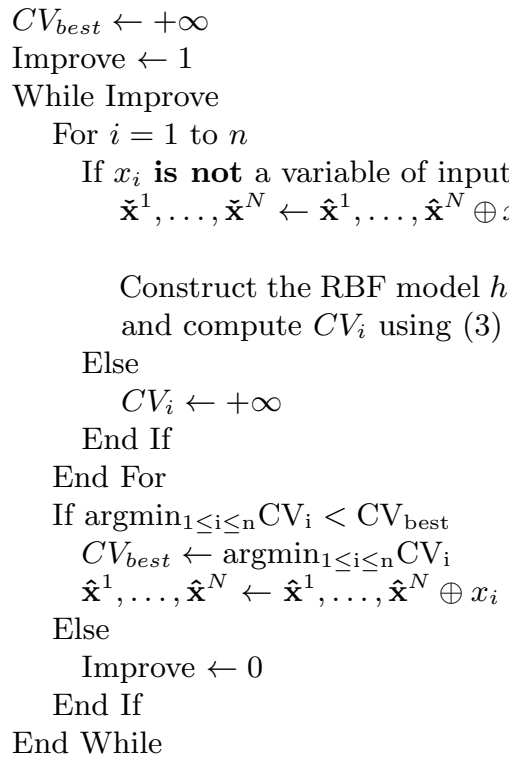

\section{Backward screening:}

Improve $\leftarrow 1$

While Improve

For $i=1$ to $n$

If $x_{i}$ is a variable of input data $\hat{\mathbf{x}}^{1}, \ldots, \hat{\mathbf{x}}^{N}$

$\check{\mathbf{x}}^{1}, \ldots, \check{\mathbf{x}}^{N} \leftarrow \hat{\mathbf{x}}^{1}, \ldots, \hat{\mathbf{x}}^{N} \ominus x_{i}$, where operation $\ominus$ removes variable $x_{i}$ from the set of input vectors $\hat{\mathbf{x}}^{1}, \ldots, \hat{\mathbf{x}}^{N}$

Construct the RBF model $h_{i}(\check{\mathbf{x}})$ of the data points $\left(\check{\mathbf{x}}^{k}, y\left(\mathbf{x}^{k}\right)\right)$ for $1 \leq k \leq N$ and compute $C V_{i}$ using (3) to measure the prediction error Else

$C V_{i} \leftarrow+\infty$

End If

End For

If $\operatorname{argmin}_{1 \leq \mathrm{i} \leq \mathrm{n}} \mathrm{CV}_{\mathrm{i}}<\mathrm{CV}_{\text {best }}$

$C V_{\text {best }} \leftarrow \operatorname{argmin}_{1 \leq \mathrm{i} \leq \mathrm{n}} \mathrm{CV}_{\mathrm{i}}$

$\hat{\mathbf{x}}^{1}, \ldots, \hat{\mathbf{x}}^{N} \leftarrow \hat{\mathbf{x}}^{1}, \ldots, \hat{\mathbf{x}}^{N} \ominus x_{i}$

Else

Improve $\leftarrow 0$

End If

End While 


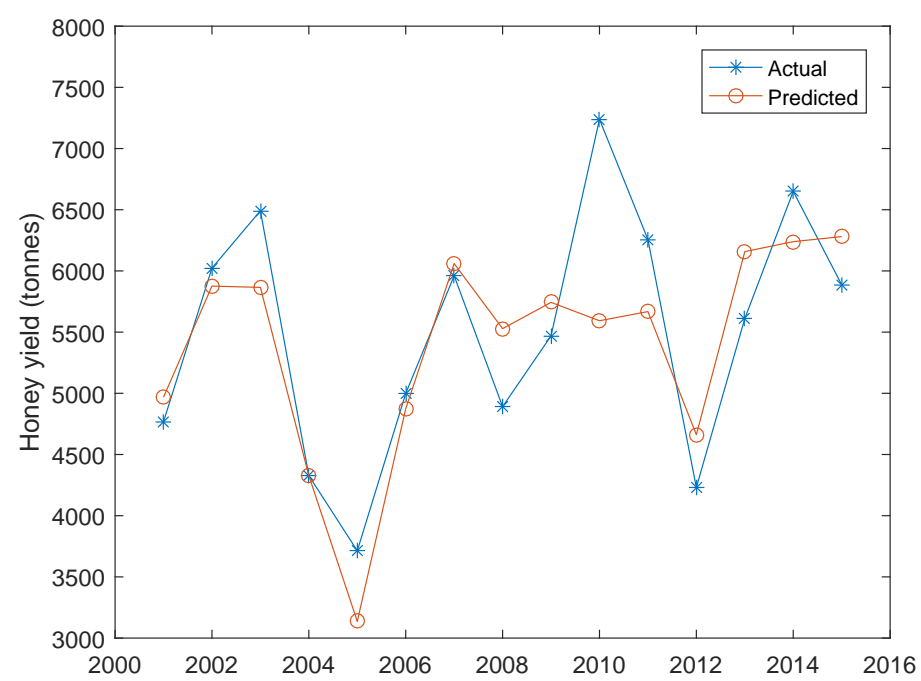

Fig. 2. Actual honey yields in Andalusia compared with RBF forecast.

The strategy sketched to forecast the honey yield in Andalusia for each of the years in study, 2001-2015, was the following:

- Remove the data concerning the year to forecast for each of the five provinces of Andalusia - Córdoba, Granada, Huelva, Málaga and Seville - guaranteeing that no bias is introduced in the results;

- Consider the remaining data from the five provinces to:

- find a subset of variables using Algorithm 2;

- fit the Thin plate RBF models using the subset of variables found;

- estimate the honey yield for that year for each province;

- Considering the average contribution of each province to the overall honey yield of Andalusia, calculate five different honey yield estimates for that year for Andalusia;

- Consider the median of the five previous predictions as the final estimate of honey yield for Andalusia in that year.

Forecast results following this strategy are displayed in Fig. 2. The mean prediction error was $7.9 \%$ which is quite good for such an irregular series. Apart from one year (2010), forecast for all the remaining years are very close to actual honey yield. Furthermore, honey yield trend is well captured. We have to highlight the importance of variable screening. Selecting a subset of variables with good predicting ability enables a better forecast. To calculate the production forecast for each year, that year is eliminated from the data for all provinces. This means that the variable screening procedure do not consider any data from 

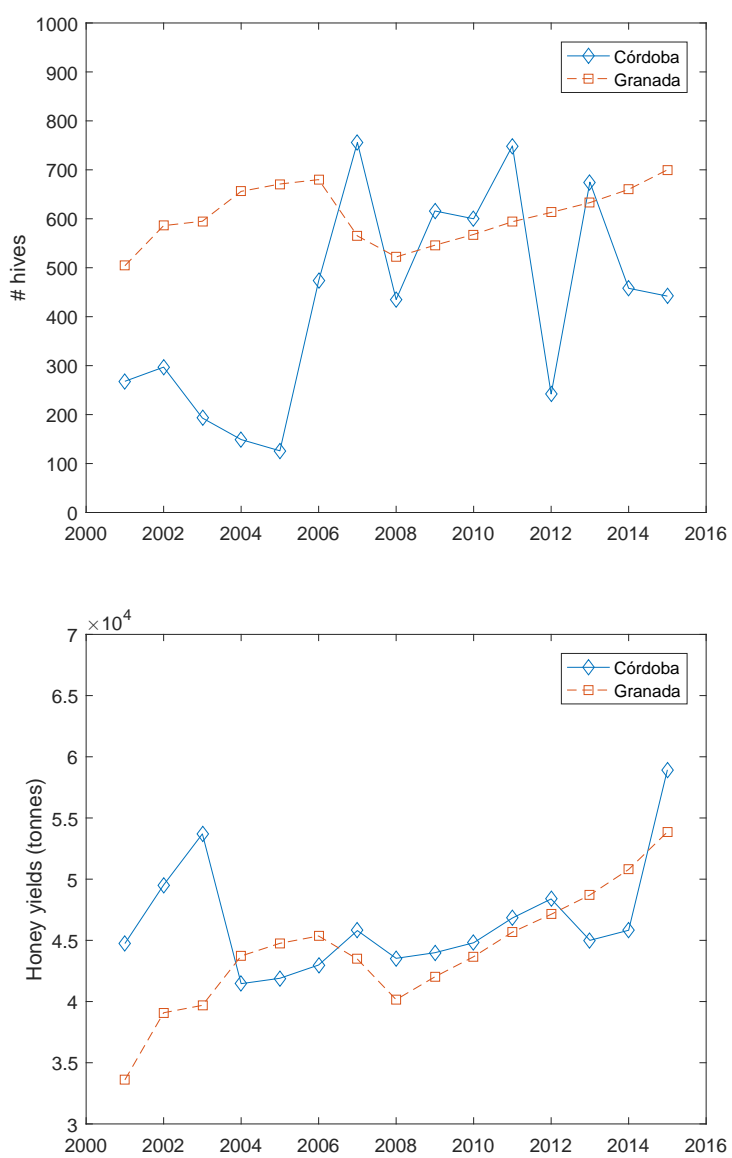

Fig. 3. Number of hives and honey yields for Córdoba and Granada.

the year to forecast. This leads to different subsets of variables being considered for the forecast of different years. Thus, it is not useful to enumerate the different subsets of predicting variables as they depend on the year (and the geographical region). Nevertheless, some variables appear more often in the different subsets including the minimum temperature in April, the maximum temperature in June and evapotranspiration in September. It is interesting to report as well that the number of hives was often absent of the subset of best predicting variables. Although more hives could be expected to lead to higher honey productions, figures show otherwise. If we plot the number of hives and corresponding total honey production for Córdoba and Granada (see Fig. 3), it is straightforward to see that larger number of hives do not correspond to an increased production. Furthermore, for the same province, increase in the number of hives randomly 
reflects an increased production. Note that, by simple inspection of Table 2 it is possible to verify that weather conditions are quite different for these two provinces which might solely explain the differences in honey yield.

\section{Conclusions}

Honey yields are difficult to predict and have been usually associated with weather conditions. Although some particular meteorological variables have been associated with honey yields, extrapolating the reported relationships to different regions of the globe or even for different temporal periods is not straightforward. Thus, the selection of weather variables should be performed using data of the specific regions to be studied and considering adequate time frames.

In this study, we propose an automated forward-backward variable screening procedure that lead to subsets of variables with good predicting ability. RBFs models were used to fit the data and guide the variable screening algorithm. RBF interpolation models can provide excellent interpolants even for poorly distributed data points. Instead of an a priori choice of a RBF basis, the numerical choice of the most adequate RBF is advised. We used the CV error as proxy of the prediction error to decide which RBF basis should be used.

For the subsets of variables obtained using the variable screening procedure, RBF models obtained high quality honey yield predictions. A set of forecasts for Andalusia, obtained from the extrapolation of forecasts for the different provinces considered, allowed a better final annual forecast obtained by excluding extreme values. The variables considered for the RBF models change for different years. Therefore, unlike other studies where specific variables are identified as the most relevant, the only conclusion that can be safely drawn is that meteorological variables are good predictors of honey production but they depend on the geographic region and the time frame considered. The reverse problem of using honey yields to acknowledge climate changes should be as interesting and challenging as the problem addressed here.

\section{Acknowledgements}

This work has been supported by the Fundação para a Ciência e a Tecnologia (FCT) under project grant UID/MULTI/00308/2013.

\section{References}

1. Anuário de Estadistica del Ministerio de Agricultura, Alimentación y Medio Ambiente, http://www.mapama.gob.es/

2. Crane, E.: The Archaeology of Beekeeping. Cornell University Press (1983)

3. FAOSTAT, http://www.fao.org/faostat/

4. Holmes, W.: Weather and honey yields. Scottish Beekeeper 75, 190-192 (1988)

5. Holmes, W.: The influence of weather on annual yields of honey. Journal of Agricultural Science 139, 95-102 (2002) 
6. Hurst, G. W.: Honey production and summer temperatures. The Meteorological Magazine 96, 116-120 (1967)

7. Hurst, G. W.: Temperatures inhigh summer, and honey production. The Meteorological Magazine 99, 75-82 (1970)

8. Instituto de investigación y formación agraria y pesquera, www.juntadeandalucia.es/agriculturaypesca/ifapa/ria/

9. Krishnamurti, B.: A brief analysis of eleven years (19281938) records of scale hives at the Rothamsted Bee Laboratory. Bee World 20, 121-123 (1939)

10. MATLAB 2016a. Natick. The MathWorks Inc., Massachusetts (2016)

11. Nelder, J., Mead, R.: A Simplex Method for Function Minimization. Comput. J. 7, 308-313 (1965)

12. Powell, M.: Radial Basis Function Methods for Interpolation to Functions of Many Variables. HERMIS: International J. Computer Maths \& Its Applications 3, 1-23 (2002)

13. Rocha, H., Li, W., Hahn, A.: Principal Component Regression for Fitting Wing Weight Data of Subsonic Transports. J. Aircraft 43, 1925-1936 (2006)

14. Rocha, H.: Model parameter tuning by cross validation and global optimization: application to the wing weight fitting problem. Struct. Multidiscip. Optim. 37, 197-202 (2008)

15. Rocha, H.: On the selection of the most adequate radial basis function. Appl. Math. Model. 33, 1573-1583 (2009)

16. Rocha, H., Dias, J.M., Ferreira, B.C., Lopes, M.C.: Selection of intensity modulated radiation therapy treatment beam directions using radial basis functions within a pattern search methods framework. J. Global Optim. 57, 1065-1089 (2013)

17. Rocha, H., Dias, J.M., Ferreira, B.C., Lopes, M.C.: Beam angle optimization for intensity-modulated radiation therapy using a guided pattern search method. Phys. Med. Biol. 58, 2939 (2013)

18. Switanek, M., Crailsheim, K., Truhetz, H., Brodschneider, R.: Modelling seasonal effects of temperature and precipitation on honey bee winter mortality in a temperate climate. Sci. Total. Environ. 579, 1581-1587 (2017)

19. Tu, J.: Cross-validated Multivariate Metamodeling Methods for Physics-based Computer Simulations. Proceedings of the IMAC-XXI (2003)

20. Tu, J., Jones, D.R.: Variable Screening in metamodel design by cross-validated moving least squares method. Proceedings of the 44th AIAA (2003)

21. Zilinskas, A.: On similarities between two models of global optimization: statistical models and radial basis functions. J. Glob. Optim. 48, 173-182 (2010)

\section{Appendix}


Table 2. The weather variables, 2001-2015, means and standard deviations (SD).

\begin{tabular}{|c|c|c|c|c|c|c|c|c|c|c|}
\hline & \multicolumn{2}{|c|}{ Córdoba } & \multicolumn{2}{|c|}{ Granada } & \multicolumn{2}{|c|}{ Huelva } & \multicolumn{2}{|c|}{ Málaga } & Sev & \\
\hline & Mean & SD & Mean & SD & Mean & SD & Mean & SD & Mean & SD \\
\hline Rainfall (mm) & & & & & & & & & & \\
\hline January & 53,2 & 37,8 & 31,8 & 23,1 & 54,4 & 36,1 & 39,3 & 39,7 & 54,5 & 35,1 \\
\hline February & 74,5 & 50,4 & 37 & 31,8 & 68,9 & 67,9 & 60 & 61,5 & 69 & 59,2 \\
\hline March & 80,9 & 74,1 & 38,5 & 23,2 & 83,8 & 58,1 & 69,6 & 50,5 & 61,6 & 59,2 \\
\hline April & 57,3 & 42,9 & 40,7 & 21,9 & 61,9 & 39,5 & 35,3 & 21,7 & 39,5 & 26,3 \\
\hline May & 36,7 & 31,1 & 34 & 19,1 & 30,4 & 30,4 & 18,3 & 17,1 & 31,3 & 32,4 \\
\hline June & 7,7 & 14,4 & 17,5 & 12,4 & 7,1 & 13,4 & 1 & 1,6 & 7,6 & 9 \\
\hline July & 0,6 & 2 & 3 & 6,5 & 1 & 2,8 & 1 & 1,1 & 2,3 & 5,3 \\
\hline August & 7,2 & 13,8 & 9,8 & 12,5 & 8,7 & 17,9 & 0,7 & 1,3 & 3,9 & 12,2 \\
\hline September & 33,9 & 31,4 & 23,6 & 15,9 & 27,8 & 30,4 & 31,4 & 32,2 & 28,5 & 22,2 \\
\hline October & 82,4 & 50,3 & 30,8 & 26 & 105,6 & 51,4 & 55 & 46 & 73,2 & 38,4 \\
\hline November & 73,5 & 57,6 & 38,4 & 23,3 & 80,1 & 67,8 & 79,6 & 70,5 & 72,8 & 52,7 \\
\hline December & 85 & 99,4 & 39,1 & 42,4 & 78 & 79,1 & 67,9 & 71,6 & 84,4 & 99,5 \\
\hline Evapotranspira & & & & & & & & & & \\
\hline January & 31,1 & 5,5 & 46,1 & 6,4 & 35,9 & 3,5 & 44 & 5,1 & 32,4 & 2,9 \\
\hline February & 44,4 & 5,7 & 54,1 & 6,9 & 50,4 & 6 & 55,9 & 5,8 & 45,5 & 5,6 \\
\hline March & 78,2 & 8,3 & 86,7 & 9,9 & 83,8 & 10,4 & 86,7 & 12,5 & 80,4 & 8,5 \\
\hline April & 108,1 & 9,2 & 107,8 & 14 & 114,4 & 10,9 & 114,7 & 11,3 & 112,4 & 9,2 \\
\hline May & 146,2 & 13 & 143,3 & 18,6 & 158,6 & 15,1 & 151,9 & 12,5 & 154,2 & 14,5 \\
\hline June & 180,5 & 9,7 & 178,2 & 12,1 & 189,7 & 15,3 & 180,5 & 9,4 & 187,1 & 10,8 \\
\hline July & 203,1 & 9,4 & 210,5 & 8,8 & 214,5 & 10,9 & 196,1 & 8,5 & 209,3 & 7,7 \\
\hline August & 181,3 & 10 & 184,4 & 15,3 & 186,3 & 8,7 & 174,5 & 7,2 & 187,1 & 7,3 \\
\hline September & 120,1 & 9 & 122,4 & 9,2 & 124,5 & 9,9 & 121,7 & 10,8 & 125,6 & 8,6 \\
\hline October & 74,2 & 6,2 & 85,3 & 9,9 & 78,1 & 6,5 & 79,2 & 8,7 & 77,8 & 6,7 \\
\hline November & 39,8 & 5 & 48,9 & 8,3 & 41,6 & 10,4 & 49,8 & 6,5 & 40,8 & 4,2 \\
\hline December & 28,5 & 3,7 & 39,3 & 5,2 & 31,5 & 3,5 & 39 & 3,6 & 29,3 & 3,3 \\
\hline Minimum temp & & & & & & & & & & \\
\hline January & 2,7 & 2,1 & 0,6 & 1 & 6,2 & 1,3 & 6,2 & 1,3 & 3,8 & 1,7 \\
\hline February & 3,4 & 2,4 & 0,6 & 1,5 & 6,3 & 1,7 & 6,8 & 1,7 & 4,2 & 2,3 \\
\hline March & 6,4 & 1,6 & 3 & 0,9 & 8,4 & 0,8 & 8,7 & 0,8 & 7 & 1,2 \\
\hline April & 8,9 & 1,2 & 5,1 & 1,1 & 10,3 & 1 & 10,7 & 0,9 & 9,4 & 1,1 \\
\hline May & 11,5 & 1,1 & 8,4 & 1,3 & 12,9 & 1,1 & 13,4 & 0,8 & 12,3 & 1,2 \\
\hline June & 15,2 & 0,9 & 13,1 & 1,2 & 16,4 & 1 & 17,2 & 0,9 & 16,2 & 1 \\
\hline July & 17 & 0,8 & 16,1 & 1 & 18 & 0,7 & 19,5 & 0,8 & 18,1 & 0,7 \\
\hline August & 17,7 & 0,9 & 16 & 0,6 & 18,5 & 1 & 20,3 & 0,9 & 18,8 & 1 \\
\hline September & 15,4 & 1 & 12,4 & 0,8 & 16,6 & 0,6 & 17,7 & 0,4 & 16,3 & 0,8 \\
\hline October & 12 & 1,1 & 9 & 0,9 & 14,1 & 0,9 & 14,2 & 0,8 & 12,8 & 1,5 \\
\hline November & 6,3 & 2,2 & 3,7 & 1,3 & 9,3 & 1,2 & 9,7 & 1,5 & 7,2 & 1,8 \\
\hline December & 3,5 & 1,4 & 1,2 & 1,1 & 6,9 & 1 & 7,2 & 0,9 & 4,7 & 1,4 \\
\hline Maximum tem & & & & & & & & & & \\
\hline January & 14,7 & 1 & 10,5 & 1,6 & 15,3 & 1 & 17,1 & 1 & 14,6 & 1 \\
\hline February & 16,2 & 1,4 & 10,8 & 1,9 & 16,2 & 1 & 17,4 & 1,1 & 15,9 & 1,3 \\
\hline March & 19,9 & 1,4 & 14,3 & 1,4 & 19,1 & 1,3 & 19,7 & 1,2 & 19,3 & 1,3 \\
\hline April & 23,2 & 1,4 & 17 & 1,9 & 21,7 & 1,2 & 22,1 & 1 & 22,4 & 1,4 \\
\hline May & 27,9 & 2,2 & 21,2 & 2,4 & 25,8 & 2 & 25,4 & 1,2 & 27 & 2,2 \\
\hline June & 33,7 & 1,4 & 27,5 & 1,6 & 30,2 & 1,3 & 29,8 & 1,2 & 32,4 & 1,5 \\
\hline July & 37,1 & 1,3 & 31,6 & 1,1 & 33,2 & 1,3 & 32,5 & 1,1 & 35,8 & 1,2 \\
\hline August & 36,8 & 1,1 & 30,9 & 1,1 & 32,9 & 1,1 & 32,6 & 1 & 35,6 & 1 \\
\hline September & 31,3 & 1,2 & 25 & 1,2 & 28,6 & 1,4 & 29 & 0,7 & 30,4 & 1,1 \\
\hline October & 25,6 & 1,7 & 20,3 & 1,7 & 24,3 & 1,6 & 25 & 1,2 & 25,2 & 1,6 \\
\hline November & 18,6 & 1,4 & 13,6 & 1,8 & 18,8 & 1,2 & 20 & 1,3 & 18,6 & 1,3 \\
\hline December & 15,2 & 1,3 & 11 & 1,6 & 15,8 & 0,9 & 17,4 & 1 & 15,3 & 1,3 \\
\hline Mean temperat & & & & & & & & & & \\
\hline January & 8 & 1,3 & 5 & 1,1 & 10,2 & 0,9 & 11,4 & 0,9 & 8,7 & 1,1 \\
\hline February & 9,2 & 1,5 & 5,3 & 1,6 & 10,8 & 1,1 & 12 & 1,2 & 9,7 & 1,4 \\
\hline March & 12,7 & 0,7 & 8,3 & 1,1 & 13,4 & 0,8 & 14,1 & 0,8 & 12,9 & 0,8 \\
\hline April & 15,8 & 1,1 & 10,8 & 1,4 & 15,7 & 1 & 16,4 & 0,8 & 15,7 & 1,1 \\
\hline May & 19,7 & 1,5 & 14,7 & 1,8 & 19,2 & 1,5 & 19,5 & 0,9 & 19,7 & 1,6 \\
\hline June & 24,8 & 1,1 & 20,2 & 1,4 & 23,2 & 1,1 & 23,7 & 1 & 24,4 & 1,2 \\
\hline July & 27,7 & 1 & 23,7 & 1 & 25,5 & 0,9 & 26,3 & 0,9 & 27,3 & 1 \\
\hline August & 27,5 & 0,8 & 23,1 & 0,9 & 25,4 & 1 & 26,5 & 0,7 & 27,3 & 1 \\
\hline September & 23,1 & 0,9 & 18,2 & 0,9 & 22,1 & 0,8 & 23,2 & 0,4 & 23,2 & 0,8 \\
\hline October & 18,1 & 0,9 & 14,2 & 1,2 & 18,7 & 1,1 & 19,3 & 0,7 & 18,7 & 1,1 \\
\hline November & 11,7 & 1,4 & 8,2 & 1,5 & 13,6 & 1 & 14,6 & 1,1 & 12,5 & 1,2 \\
\hline December & 8,5 & 1 & 5,5 & 1,3 & 10,9 & 0,9 & 12,1 & 0,7 & 9,5 & 1,1 \\
\hline Relative humid & & & & & & & & & & \\
\hline January & 81,9 & 5,8 & 62,4 & 8,6 & 78,8 & 5,1 & 70,7 & 4,4 & 81 & 6,1 \\
\hline February & 77,4 & 7,5 & 62,5 & 7,9 & 74 & 7,9 & 68,2 & 4,9 & 76 & 9,2 \\
\hline March & 71,8 & 6,9 & 59,9 & 7,3 & 71,4 & 6,8 & 67,1 & 7 & 70,8 & 7,6 \\
\hline April & 67,1 & 5,9 & 60,2 & 6,9 & 68,4 & 6,3 & 63 & 7,1 & 65,4 & 6 \\
\hline May & 57,7 & 7,2 & 54,3 & 8,4 & 59,2 & 5,2 & 56,7 & 5,6 & 55,4 & 7,3 \\
\hline June & 47,1 & 4,4 & 44,3 & 5,5 & 52,3 & 4,8 & 51,5 & 3,8 & 47,6 & 4,9 \\
\hline July & 38 & 4,5 & 34,5 & 4,4 & 47,1 & 4,5 & 51,2 & 4 & 40,3 & 5 \\
\hline August & 39,8 & 4,2 & 38,5 & 4,6 & 51,1 & 3 & 55,3 & 3,6 & 42,3 & 4,4 \\
\hline September & 53,8 & 6,4 & 51,9 & 6,1 & 63 & 7,1 & 61,9 & 4,3 & 55,7 & 7,3 \\
\hline October & 69,2 & 6,4 & 57,6 & 6,7 & 71,7 & 4,9 & 69,6 & 3,7 & 67,4 & 5,3 \\
\hline November & 78 & 7,5 & 63,2 & 10,3 & 73,6 & 7,7 & 70,5 & 6 & 74,4 & 8,3 \\
\hline December & 81,6 & 5,3 & 64,3 & 5,4 & 78,7 & 5,4 & 73,2 & 3,7 & 80,2 & 4,9 \\
\hline
\end{tabular}

